Esta obra está bajo una Licencia Creative Commons Atribución-NoComercial-Compartirlgual 4.0 Internacional

(c) (1) (8) ()

El clamor de no agresión de Joan Baez y Mercedes Sosa para los oídos argentinos de 1974

David Orjuela

DOI: https://doi.org/10.24215/16696581e217

\title{
El clamor de no agresión en Joan Baez y Mercedes Sosa para los oídos argentinos de 1974
}

\section{Joan Baez and Mercedes Sosa' non aggression outcry into argentinian ears en 1974}

\author{
David Orjuela davidorjuela19@gmail.com \\ https://orcid.org/0000-0002-4290-6076 \\ Universidad de Buenos Aires (Argentina)
}

\section{Resumen}

Este trabajo caracterizará el proceso micropolítico sucedido en el recital que la cantante estadounidense Joan Baez dio en Buenos Aires en 1974, el cual contó con la participación de 
la cantante argentina Mercedes Sosa. El evento sucedió en medio de una crisis política inédita, alentada por luchas ideológicas polarizadas que incubó un estado de violencia permanente. No obstante, ese recital venía como una actualización de, primero que nada, un estado de solidaridad, donde la denuncia social emergía como resultado de una lucha no violenta, de índole más experiencial que formal. Tal posición provocó desencuentros entre la producción artística y una recepción dóxica, dada la distancia percibida entre lo propuesto en el discurso musical de las artistas, y el marco sociopolítico del país. En el recital, el público devenía expectante de determinados efectos de sentido, en parte debido a la estandarizada relación entre contenidos costumbristas y reivindicaciones sociales, a su vez relacionadas con ideologías políticas específicas en el país y en la región. En definitiva, se tomará ese recital como estudio de caso para dar cuenta de cómo una escucha viciada puede acallar la vitalidad del arte, no solo para caracterizar una sociedad, sino para ir más allá y proponer mutaciones políticas oportunas.

Palabras clave: recital; recepción; música; arte; mutaciones políticas.

\section{Abstract:}

This work portrays how micropolitical processes present in Joan Baez music toiled at her 1974 alive performance in Argentina. The event happened on September the 12th and was accompanied by the Argentinian singer Mercedes Sosa, in the middle of a wide political crisis, encouraged by ideological struggles, both farmers of an ongoing state of violence. As the event set forth an update of the idea of a non-violence fight against social problems, it brought out a lack of understanding between the artistic offer on the stage and a doxic audience, anxious of specific sound effects due to certain standardized relation between traditional ideologies and social claims. Hence, this alive performance will be taken as a case study, for giving an account of how some flawed listening habits manage to suppress the permanent vitality of art, not just for typifying current societies, but for going beyond and putting forward prompted political mutations.

Keywords: alive performance, audience, music, art, political mutations. 


\section{Introducción}

El 12 de septiembre del año 1974, Joan Baez cantaba en el teatro Luna Park. El recital hacía parte de un set de presentaciones que incluía otra fecha en Buenos Aires y una en Rosario. La artista llegaba a Argentina en medio de grandes expectativas del público por escucharla, motivado por su perfil artístico híbrido (una suerte de folk-rock-pop-revolucionaría-masiva). Al mismo tiempo, aterrizaba en un momento dónde la Argentina presentaba, tanto en el plano material como simbólico, particularidades y novedades de una gravedad especial (Franco, 2012, pp. 168-184). Concretamente, en ese mismo año, el primero de julio, el líder Juan Domingo Perón había fallecido; dicho acontecimiento terminó de desarticular una sociedad sumergida en una crisis plural, a la vez social y política. En definitiva, fue una época de desencanto, donde el país transitó entre una sociedad movilizada para el cambio y la guerra interna entre populismos, hasta llegar a la agonía y disolución de un modelo populista (1). En el inicio del último momento, cuando el sindicalismo tradicional, la extrema derecha, la guerrilla y el avance de las fuerzas armadas hacia el poder político se configuraban como los actores políticos sociales más importantes, Joan Baez ofrecía tres recitales en el país (Svampa, 2007, pp. 384,385) (2).

El evento hacía parte del tour de lanzamiento de su álbum "Gracias a la vida" (1974), cantado totalmente en español y donde interpretaba canciones populares de Chile, Cuba, México y España. Tanto en el recital del 12 de septiembre como en los otros dos, Baez cantó la canción "Gracias a la vida" junto a Mercedes Sosa, quién en 1971 había lanzado un álbum en homenaje a la artista Violeta Parra (1966). Su recital se erigía como la actualización de un poderoso mecanismo de constitución de subjetivaciones políticas (3), contenido en su producción musical de estudio. Desafortunadamente, la "falta" de oído del público acalló esa capacidad para evidenciar los vicios políticos de la época, provocadores de la violencia, y así probablemente virar el destino del país.

En este trabajo se describirá semióticamente la serie música - producción musical - recitalrecepción. Luego, se caracterizarán algunas condiciones sociológicas de la producción musical de Joan Baez y Mercedes Sosa para el año 1974. Finalmente se evidenciará esa especie de estrechez pragmática del público en general, asistente al Luna Park, que impidió entender en toda su extensión la organicidad de la propuesta artística, tanto de Baez como de Sosa. Es paradójico que un discurso, primero que nada, de no agresión, no haya sido suficiente para detener la corporización de la violencia como política pública en el país. En definitiva, este trabajo se esforzará por evidenciar algunos problemas que emergen cuando se practica una 
recepción menguada del arte, especialmente la disminución de sus posibilidades para insuflar en las sociedades mutaciones convenientes para reformar hábitos políticos.

Aspectos teórico-metodológicos: el signo musical, el recital y su recepción

\section{La música como signo regulador}

La producción musical y el recital, uno de sus medios de reproducción, emergen dentro de un gran iceberg cultural: la música. La música, las músicas o el discurso musical, hacen referencia a un gran signo regulador que contiene y controla todo lo que pueda ser contemplado como "musical". Ahora bien, ya sea como lenguaje, como sistema o como discurso, el signo es dependiente de la práctica social, generadora de la semiosis o creación de significado. En el caso de la música, se trata de un sistema semiótico que organiza las series sociales mediante unidades constitutivas, los sonidos, los cuales son regidos por notaciones (tiempos y compases) y las reproduce con tecnologías que permiten la emergencia de los géneros musicales.

Efectivamente, la manifestación del signo música, como cualquier signo, se mueve en los órdenes de representamen (ícono), objeto, e interpretante (convención). Es decir, con base en una cualidad material que indica la forma perceptual en que ese signo consiste, éste puede hacer referencia a cualquier combinación efectuada dadas sus relaciones imaginarias, indiciales o convencionales con su alrededor. En el caso de la música el número de elementos con lo que ésta entra en relación son casi infinitos; y sus efectos particulares provocados en la mente del intérprete en una situación concreta de comunicación, dentro de un contexto determinado, distintos (4). En definitiva, el efecto interpretante de "música" es el resultado de la organización de las relaciones de un proceso construido con base en relaciones lógicas (5), formadas desde algún o algunos efectos particulares y con predominio de alguno de los tres órdenes de significación: similitud (ícono), relación existencial o deíctica (objeto) o símbolo (convención) (6).

\section{El recital}

Por su parte el recital es una actividad práctica que, a diferencia de la grabación, articula de forma más específica la producción real en actores específicos. Es un momento cumbre de la producción musical, convocante de una audiencia que inscribió en su cuerpo el artefacto musical. Asimismo, es un evento directamente evocador de las actividades llevadas a cabo en una de las invenciones urbanísticas originales de la antigua Grecia, el ágora. Aquellos fueron centros de comercio, religión, política y arte; todas estas actividades mediadas por, de acuerdo 
a los vestigios antropológicos y referencias literarias, la ejecución de música vocal y/o instrumental frente a un público (González, 2003, pp. 133, 134).

Por consiguiente, siguiendo un planteo semiótico, la recitación, la repetición, la carne en un estado motor, el cuerpo en estado comunicativo que se manifiesta en el recital, son el resultado de la condensación de significaciones generadas al reproducirse el signo "música". No obstante, en el caso particular de la música, lo anterior no quiere decir que los cuerpos son movidos por un significado "lingüístico" particular. Al contrario, al compartir su unidad constitutiva (los sonidos) con otros sistemas semióticos (la plástica, la danza, etc.) emerge una disposición distinta en la transición entre reconocimiento (sistema semiótico) a comprensión (sistema semántico), que se denominaría significancia (Benveniste, 1977, p. 49). En definitiva, un recital deviene en una estación sincrónica de llegada de la cadena infinita de traducciones interpretaciones de "música", donde la capacidad del sonido para crear comunidad se manifiesta.

Ya dentro del recital, la fuerza formal de significación del signo es alterada por el desarrollo de una performatividad propia. Es decir, ya hay performatividad en la oferta discursiva, porque es la característica poseedora del máximo poder de interpelación. Este componente, junto a los elementos formales, permite la emergencia de modos diversos de coherencia, y generan posiciones de sujeto variadas, incluso contradictorias. No obstante, en el recital, el enunciador del discurso musical pasa a ser el performer de una alianza establecida a priori, entre determinadas identidades imaginadas y narradas, y la práctica musical. Es decir, el recital deviene en etapa de cierre de la negociación de identificaciones narrativas e imaginarias particulares ancladas, tanto en la producción musical como en el cuerpo material de la audiencia (Vila, 2014, p. 4). Sin embargo, dada la negación del carácter fragmentario de esas articulaciones, la negociación puede no salir como se espera y generar una gramática del reconocimiento donde la recepción y reconstrucción de las materias significantes se desfasan con parte de la gramática de producción ¿Cómo es esto?

\section{La percepción}

Se trata en general de la circulación del evento cultural desde la producción al reconocimiento, desde dos efectos de sentido: efecto de conocimiento (sentido discursivo-textual) y efecto ideológico (Verón, 1984, pp. 43-51). En una instancia prima, las gramáticas de reconocimiento se mueven por el mismo conjunto de significantes dados en la gramática de producción, debido a la compartición espacial-temporal con las materias significantes. Sin embargo, junto a los significados inminentes, el signo producido es lanzado a un proceso de metaforización y se expande a significaciones emergentes y trazas que pueden actuar de trasfondo. Esa 
disonancia sucede en el momento en que los esbozos de identidades narrativas se tornan en experiencias culturales individuales. Este acontecimiento sucede, tanto en el momento de la inmediatez asociado al disfrute, como al posterior, en el que se negocia el significado discursivo dentro de otras semióticas organizadoras del espacio social (Vila, 2014, pp. 63-65). En suma, no obstante la gramática de producción parametriza la percepción, la audiencia de la producción cultural evalúa, situacional y provisionalmente al signo productor y produce su propio signo, resultado de la aplicación de la fluctuante gramática de reconocimiento.

Ahora, las funciones del evento cultural en la práctica social quedan estandarizadas gracias a mediaciones que orientan la axiología de la producción musical y atestigua sus funciones políticas y éticas desde asociaciones culturales específicas, es decir desde la arista puramente simbólica y axiológicamente formada del signo. Ese constreñimiento posterior de la discursividad, al valorizarse socialmente, refiere a las categorías identificatorias, y a las perspectivas estéticas e ideológicas que, al final, regularan la interpretación general. Así, la capacidad expresiva de la producción musical, cuyas interpelaciones se agencian en la experiencia de vida, se somete a la regulación ética grupal. Esa reproducción del signo permite la entrada solo a entidades unificadas, las cuales a su vez gestionan interpelaciones homogéneas y espacios ontológicos no negociables. En definitiva, pese a que la producción musical es una entidad fragmentada, constituyente de una cantidad ilimitada de identidades narrativas, se condensa y se transforma en ciertas posiciones de sujeto gracias a esbozos narrativos mediados, derivados de un espacio - tiempo particular (exclusividad sincrónica).

¿Qué pasa con el resto de las interpretaciones? Siguen allí, en remojo, latentes, rezagadas de aquellas que fueron mediatizadas. En efecto, la atención masiva está puesta en el dentro del conjunto de discursos mantenidos por series políticas y culturales vigilantes del sentido. Por su parte, los discursos generados fuera de ese circuito, compactos o en etapas de desarrollo, aguardan a ser encontrados y enunciados por gramáticas del reconocimiento emancipadas de aquellas series políticas y culturales sincrónicas.

\section{Condiciones de la producción discursiva de Joan Baez y Mercedes Sosa hasta 1974}

Si "música" es un signo regulador, la producción musical de ambas artistas se ubicaría como condensación o subsigno. Desde esa condición, sería un artefacto cultural que manufactura modos-otros de coherencia narrativa, afectiva, resonante, resultado del anclaje en un cuerpo subjetivo, y la agencia de éste en un cuerpo social. En efecto, el sonido, las letras, el performance, y hasta los comentarios que sobre esto se hagan, transitan entre bases discursivas-textuales y participan en procesos de construcción identitaria propia y del mundo 
(Vila, 2014, pp. 50-60). En definitiva, se adecua como una parte de la realidad, manipulándola, al producir subjetividad que rechaza o refuerza interpretantes provenientes del espacio semiótico, articulándolos al mismo tiempo con su estado de nuevo signo, cuya gramática de producción se encuentra lista para ser reconocida.

Consideramos entonces que el haz de condiciones de producción del signo "producción musical de Joan Baez y Mercedes Sosa hasta 1974" (SB1974), es constituido por la elaboración social de la época. Es decir, incluye tanto lo sociológico como propiedades formales de carácter organizador de conocimientos y significados dentro de la materialidad misma (Pêcheux, 1978, p. 234). Por el lado de la organización interna, sus reglas de proyección entre situaciones y posiciones, así como las re-presentaciones anticipadas del signo productor, se pueden caracterizar con métodos provenientes de la Lingüística. Pongamos por caso los procedimientos aportados por la Lingüística Sistémico - Funcional. Este modelo gramatical trata de la relación intra e intertextual de una materialidad con el contexto de situación; ésta es caracterizada mediante meta-funciones semánticas que, a nivel extralingüístico, incluye el envolvimiento musical. Por lo tanto, en la configuración declarativa se localizan tres niveles de sentido que corresponden al qué o de qué se habla (el campo), quienes hablan (tenor) y al cómo se habla o expresa a nivel organizacional (modo). Así, el análisis de los diferentes estratos lingüísticos en las letras aproxima la infinitud de mundos imaginados, interpelaciones hegemónicas, étnicas, de usos de convenciones que, junto con las denotaciones obvias, se muestran en una materialidad dada. En suma, permite ver más claramente la repercusión del contexto social en la gramática del texto y viceversa (7).

Sin embargo, aquí nos focalizaremos en algunas situaciones del contexto sociológico de producción de BS1974, desencadenantes de lo recepcionado por la audiencia de ese tiempo, en términos de sentido, y al mismo tiempo generadora de la expectativa convocante de buena parte de los asistentes al recital.

Con referencia a sus elementos identificatorios más definidos, éstos se yerguen sobre categorías diacrónicas. La mirada se inclina primero a las transacciones discursivas hegemónicas, constituyentes de prácticas sociales y políticas; en este caso, las de la década del setenta del siglo XX en el continente americano. Efectivamente, se trata de un discurso (8) generado en un periodo que Hobsbawm (1999) subrayó como el de la "transformación mundial mayor y más intensa, rápida y universal de la historia de la humanidad". Concretamente, uno de esos cambios trascendentales fue el radicalismo político, el cual aconteció primero en los países atrasados y dependientes y luego en los desarrollados (pp. 291, 293, 300, 302, 304). Al respecto, América Latina vivió intensamente el conflicto político entre Estados Unidos y el bloque comunista. Por ejemplo, muchos países de la región continuaban o empezaban 
gobiernos dirigidos por militares, quienes tenían la misión de poner en práctica un régimen que combinara seguridad con desarrollo, lo cual suponía emprender una guerra "contra revolucionaria" en el continente (9).

Al mismo tiempo y como resultado del escenario social, los debates sobre el papel del artista en el desarrollo de las sociedades viraron. Por un lado, emergieron artistas que buscaban ser reproducción fiel del flujo europeo y estadounidense. Por otro, trabajaron desde lo ofrecido por sus geografías y ambientes, en un contexto nacionalista, popular, indigenista y folclórico. Paralelo a estos extremos, se empezaba también a discutir fuertemente la ontología de una crítica artística, que sirviera de espacio de despliegue para el arte latinoamericano (Paz, 1977, p.23). Así, algunos parámetros fenomenológicos de revelación-creación (Rodríguez, 1977, p. 33), o de resistencia sin remedar para ser aprobado ni perderse en un folclorismo banal (De Szyszlo, 1977, p.37) (10), sino para trabajar para el público, las sociedades, es decir, con función social, fueron también enunciados.

Dentro de esa dinámica, Joan Baez formó parte del movimiento denominado como "folk revival". Desde allí, se creó un estilo que se desenvolvió con soltura en dos circuitos: en el circuito de la canción social, que convocaba a la sociedad a manifestarse contra los problemas que le afectaban; y en el circuito pop. Llama la atención el poder de convocatoria que Bob Dylan, Joan Baez y otros causaron. Reflexiones sobre la guerra, los derechos civiles, etc., en un mundo que ni los educadores de estas personas, ni sus padres, estaban preparados para entender, pasaban por una gran audiencia. Igualmente, esta nueva escena del pop, que esparcía explícitos mensajes de inconformismo social, se combinaba con giros que reivindicaban el uso de drogas sicotrópicas, experiencias sexuales excéntricas y en general reivindicaban las libertades individuales (Rosenstone, 2016, pp.133,134). Y este fue el punto de enlace con otro movimiento musical - cultural trascendental, originado para la década del cincuenta en Estados Unidos: el rock (11).

Por su parte, Mercedes Sosa y otros artistas recién empezaban a configurar un terreno cultural de lucha por la igualdad de derechos en Argentina. No obstante, al igual que su colega norteamericana, se convirtieron al mismo tiempo en moda. En ambos casos, la atmosfera de renovación, juventud, militancia y frescura, que los festivales organizados generaron, se hizo masiva gracias a los medios de comunicación. De esta manera, el folclor entró en el mismo tren de otras músicas como el tango, o el rock y el pop anglosajón y nacional. Pero con una diferencia importante con respecto a Estados Unidos: estaba más definida políticamente. Es decir, en términos partidistas, lo cual se desarrolló junto con el andar artístico. En suma, en esa época emergió la clara posibilidad de aunar el arte renovado a una política renovada, que fue siendo tachada de forma reduccionista al aparato ideológico de izquierda (12).

Question, Vol. 1, N. ${ }^{\circ}$ 64, octubre-diciembre 2019. ISSN 1669-6581

Instituto de Investigaciones en Comunicación | Facultad de Periodismo y Comunicación Social | Universidad Nacional de La Plata La Plata | Buenos Aires | Argentina

Página 8 de 16 
De esta forma, para la década del setenta, la performance de estas artistas fue asociado a una manifestación política protestante, militante y masiva, customizada de acuerdo a la realidad política local. En el caso latinoamericano, las expectativas por escuchar en vivo a Baez se acrecentaron debido al lanzamiento del álbum "Gracias a la vida" en 1974, interpretado todo en español y con una selección de canciones protestantes representativas. Por su parte, para 1974, Mercedes Sosa estaba interpretando en sus giras su álbum "Traigo un pueblo en mi voz" (1973). En ambos casos, tanto Baez como Sosa, incluían la canción "Gracias a la vida", del álbum homenaje a Violeta Parra (Sosa, 1971, Baez, 1974) (13).

Un poder interpelativo emancipado excluido por una recepción "reduccionista"

En SB1974 tenemos agencias emocionales imprescindibles y efectos corpóreos tanto en la inmediatez como en el despliegue psíquico de la materialidad. En el caso de Mercedes Sosa y Joan Baez, la afectividad del artefacto musical se agenció en un cambio en el tejido de la sensibilidad y una consecuente crisis de sentido de las referencias. Las letras de sus canciones y la forma musical se ubicaron dentro de un espectro de recepción que incluyó audiencias de todo tipo. Para la década del setenta, eran artistas con entrada al registro culto de la música, masivas -es decir, con una audiencia que solo se entretenía con su trabajo -, y políticamente identificables como antimperialistas y contraculturales (Karush, 2017, pp. 142-145).

Pero esa interpelación transnacional contenida en la producción musical fue evidentemente disminuida debido al desarrollo de series sociales superpuestas. O sea, la base afectiva de SB1974 fue asaltada por recepciones que la encaminaron por la política partidaria, y con ella a determinismos ideológicos socialmente exclusivos. Las identidades narrativas emergentes, que convocaron colectivamente, terminaron siendo colusiones emocionales que articularon axiológicamente solo valores sociales de superficie. En definitiva, las significancias interpelativas que se enfocaban en una trama narrativa más orgánica, es decir, en "nuevos posibles" de la acción artística de BS1974, quedaron hundidas. Los aspectos semióticos que apuntaban a causar transformaciones del paisaje cultural del continente, tales que establecieran nuevos principios de relación con el otro, se ignoraron.

En efecto, se pretendía primero afectar micropolíticamente, así tal vez lo macro entrara a una fase de modificaciones excéntricas. Esto es, no era su interrelación con series políticas y sociales sincrónicas lo más relevante, políticamente hablando. Más bien, su gran valor era la gesta de una axiología musical generadora de regresiones parresíacas, acéfalas, que recogieran compulsiones para modificar mecanismos de base de funcionamiento social y 
centrados más en un "cuerpo vibrátil" (Rolnik, 2006, p. 11) (14) ¿Qué escuchó entonces la audiencia en el recital de Joan Baez ese jueves de septiembre de 1974?

\section{Lo que se escuchó en el recital}

En el recital ninguno de esos efectos se hizo presente. En el segundo semestre de 1974 Joan Baez se presentó en el Luna Park ante una audiencia que se podría enmarcar en dos grupos sociales predominantes: el universitario y en menor medida el obrero. Estos a su vez se podrían subdividir en tres grupos: los fans del rock, quienes iban a ver a una estrella mundial; los políticos radicalizados (anarquistas y militantes de izquierda), quienes, sin distinguir el género musical de su preferencia, iban a presenciar el espectáculo de una cantante calificada de "revolucionaria"; y los folcloristas, que iban a ver y oír a la exponente más importante del folk norteamericano. Todos eran afines a algún aspecto de su actividad artística, más la razón que se impuso para escucharla era el clima partidariamente politizado en la Argentina (Franco, 2012, pp.281-329) (15). Clima que reclama de los músicos ser intelectuales orgánicos y dejar la candidez, apoliticidad, tibieza y escapismo. Había igual una resistencia a esa posición desde el lado musical, en tanto reivindicativo de la autonomía del campo artístico (Alabarces, 1993, pp. 59-62).

En una entrevista reciente, Baez contó una anécdota que marcó el tenor de la recepción del recital. En su primera visita al país, el público se había enojado porque ella dijo que la tortura se siente igual si viene de izquierda o de derecha. En ese momento, Mercedes Sosa entró al escenario a defenderla de los improperios y a reivindicar sus palabras (2017). En el recital del Luna Park cantaron "Gracias a la vida", y el repertorio tuvo más canciones en español, así como sus clásicos "blowing in the wind", o "we shall overcome". La revista Pelo, reportó que la audiencia salió insatisfecha y señaló peyorativamente la postura de la artista en reivindicar la lucha no violenta a favor de los derechos humanos y de no entrometerse en asuntos más internos del país (Ripoll, 1974). La lucha armada como método legítimo de acción política, la actitud antiestadounidense imperativa para considerarse "tercer mundo", así como la violencia estatal que venía del anterior gobierno militar y estaba más vigente que nunca durante el periodo peronista, cercenó todos los otros esquemas narrativos alternativos que el signo productor ofrecía (Franco, 2012, pp. 168-184) (16).

Una paradoja había acontecido en ese recital. El colectivo que previamente había establecido una alianza entre sus esquemas imaginarios y narrativos y la oferta discursiva del signo productor había salido defraudado políticamente, efecto generado por la asimetría entre todo el hacer del artefacto musical y el hacer presupuestado (Frith, 1998, pp. 203-206). Esto es, la performance en el recital, un proceso social-comunicativo, se condijo con el performance 
auditivo del colectivo asistente. Los esquemas narrativos de la época legitimaron solo una forma de lucha, solo una forma de uso de la música, la cual evidentemente Joan Baez y Mercedes Sosa querían superar desde la actividad artística, aunque eso fuera calificado de "rebeldía inofensiva". La guitarra acústica solitaria de Baez, su dulce voz, y su canto en inglés, no ayudaban precisamente a formar posiciones políticamente violentas. Tal vez la audiencia que presenció el recital podría haber adoptado tal acción corporal on stage y haber mutado hacia una otra política revolucionaria, comprometida con niveles estabilizadores de la sociedad, resultado de un intercambio simbólico excéntrico.

Figura 1: Performance narrativo - contexto de producción

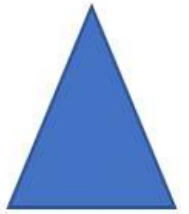

Gramática de producción del signo musical: contenedor de parámetros semióticos de funcionamiento 0 significaciones.

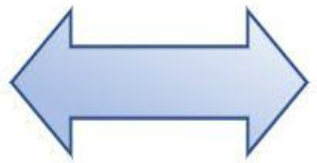

Mediación de tecnologías de difusión y comunicación que producen regulaciones éticas grupales.

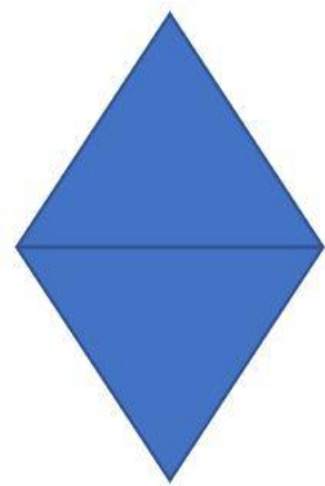

Signo musical recepcionado 1 . Gramática estandar de reconocimiento.

Figura 2: Performance auditivo - Contexto de representación

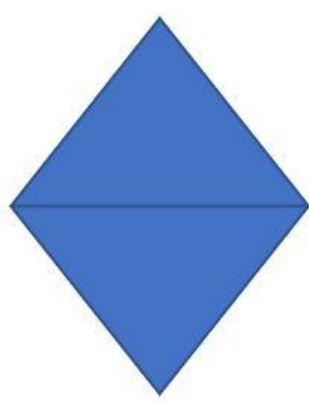

Signo musical recepcionado 1

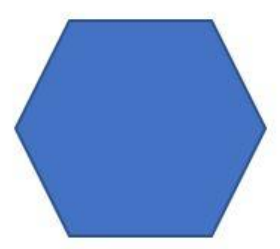

Recital: E1 contexto de producción se enmaraña con el contexto de representación. Se gesta otra escena de enunciación con más actores: narrador (del texto musical), enunciador real en tarima, el públice asistente y el sonido en vivo.

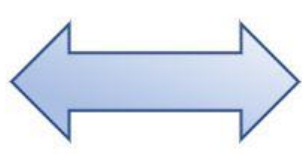

Participación de los espacios tecnológicos de difusión y comunicación, mediadores y moldeadores de la opinión.

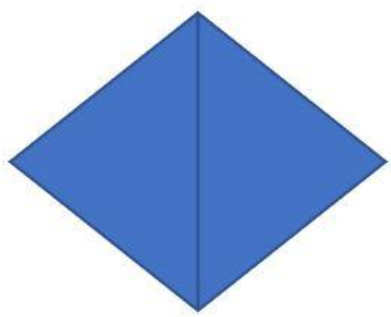

Signo musical recepcionado 2 . La gramática de reconocimiento sufre alteraciones que defraudan o restituyen elementos del primer signo recepcionado 


\section{A manera de conclusión}

En este artículo se analizó la producción y reproducción de signos musicales, y especialmente se trabajó en dar cuenta de las inconsistencias entre gramáticas de producción y reconocimiento, dados los cambios entre condiciones de producción y de representación. Faltó un análisis más exhaustivo a las letras de las canciones que fueron parte del recital, es decir su complejidad melódica, armónica, rítmica y técnica. De todas maneras, quedó en evidencia que la actividad artística-cultural es tal vez la fuente más verídica de producción y reproducción social, imprescindible para dar cuenta del devenir social y al mismo tiempo revolucionar políticamente al mundo.

Como corpus, se trabajó en el proceso micropolítico sucedido en la primavera de 1974, donde Joan Baez y Mercedes Sosa cantaron en el coliseo Luna Park en Buenos Aires. Desde lo teórico, se hizo un planteo de lo semióticamente implicado en un recital: la música como un gran signo regulador que contiene y controla, la producción musical de ambas artistas como condensación o subsigno, y el recital como una actividad práctica que, a diferencia de la grabación, articula de forma más específica la producción real en actores específicos. Es decir, es un dispositivo que suele concentrar gramáticas estándar de reconocimiento mediadas y generadas por tecnologías de difusión, las cuales moldean regulaciones éticas grupales. Desde esa instancia, el recital se ubica como un artefacto cultural que busca otros modos-otros de coherencia narrativa, afectiva, resonante, resultado del anclaje en un cuerpo subjetivo, y la agencia de éste en un cuerpo social.

Dentro de esa dinámica, el recital puede convertirse en un lugar de desencuentro, entre lo esperado de la materialidad musical y lo desplegado en vivo. Esto acontece porque las condiciones de producción se transforman en condiciones de representación. Estas últimas incluyen, no solo a la materialidad, sino al enunciador de ésta, quien no necesariamente es el narrador del texto musical y al público, quien recepcionó previamente el producto musical mediado por reguladores éticos sincrónicos. Efectivamente, en el trabajo se evidenció que, en general, la audiencia asistió al recital de Joan Baez porque ya había negociado y corporizado previamente unas identificaciones narrativas e imaginarias particulares ancladas en la producción musical, y omitido otras. En definitiva, el recital conllevó la gesta de una segunda gramática de reconocimiento, otro lugar de recepción y reconstrucción de las materias significantes. Y allí se ignoró la parte de la gramática de producción contenedora de elementos constituyentes de subjetivaciones políticas no violentas.

En efecto, nos concentramos en dar cuenta de cómo la recepción de esta producción cultural en el recital ya había construido una posición análoga a la reflejada en conductas y decisiones 
políticas que dictaron el destino social del país para los años subsiguientes. Aquella posición consistía en "no escuchar" un discurso revolucionario, pero de no agresión, de revelacióncreación, o de resistencia, sin remedar para ser aprobado ni perderse en un folclorismo banal, sino para trabajar para el público, las sociedades, es decir, con una función social singular. En suma, la omisión de esos elementos particulares simplificó la corporización de la violencia como política pública en la Argentina de la década del setenta.

Notas

(1) Para una profundización sobre el populismo véase Charaudeau (2009, pp.253-279).

(2) Véase también Delgado (2016, p.25).

(3) Las subjetivaciones políticas son procesos de significación y emergen como opción deconstructiva de las relaciones entre objeto-sujeto. El concepto se usó para, entre otras cosas, denunciar la condición de "sujeción" de las personas a la Historia, y como una condición paradójica, consecuencia de la implementación de esta clase de procesos instantáneos y "escabullantes", la cual conlleva a delinear la emergencia de determinados sujetos, movimientos, o comunidades políticas. Asimismo, su recorrido histórico-filosófico se enfocó en el último tiempo en la emergencia de resistencias, es decir subjetivaciones por oposición de los individuos a poderes que intentan configurarlos o normalizarlos. (Althusser 1998 y 1967; Foucault 1991; Rancière 1974).

(4) Ver Pierce (1987, parágrafo 2.228).

(5) Ibíd. pp.160, 180, 181, 302, 303, 416-419. "Un proceso semióticamente construido pretenderá manejar una lógica exacta, la cual comprende una doctrina de fijación de la creencia estable que se basa en observaciones perfectamente indubitables, y en el pensamiento matemático, es decir, diagramático e icónico". (306; cursivas en el original). "Su verdadera utilidad reside en la ayuda que presta y en el apoyo a la mente, al proporcionar diagramas concretos sobre los que experimentar, en la solución de los más difíciles problemas de la teoría lógica" (417).

(6) Ver Peirce (1931-1958, Párrafos 2.233-2.2240).

(7) Para una introducción al tema véase Ghio (2008)

(8) Discurso en una acepción más amplia, se considera no una estructura arbitraria, sino "la actividad de sujetos inscriptos en contextos determinados". Asimismo, Discurso, sin plural, supone la articulación del lenguaje según parámetros de orden no lingüístico. Desde esa concepción general, se entra en una serie de oposiciones, en las que toma valores más precisos. Por ejemplo, como oración o unidad lingüística, enunciación o unidad comunicativa, 
como lengua o sistema de valores virtuales, o texto, cuya asociación con el contexto concibe al discurso. La base discursiva-textual se refiere a los valores que toma como enunciado; es decir, tanto la estructuración lingüística, como el análisis lingüístico de las condiciones de producción. Ver Maingueneau (2008, pp. 37-38).

(9) Esta política se conoció como la Doctrina de Seguridad Nacional (DSN). Para revisar la interpretación de ésta en el caso argentino véase López (1987).

(10) Véase además Traba (2005).

(11) Véase Dylan (2004).

(12) Véase García, Greco, Bravo, (2014, p.91), Turfó (2010) y Ugarte (2010).

(13) Para escuchar el repertorio de Mercedes Sosa para ese año, véase, por ejemplo, Sosa (1974)

(14) Véase también Rolnik (2006).

(15) Véase también Pujol (2003).

(16) Esa politización violenta e intolerante en el país se pudo sentir, por ejemplo, en el último álbum del grupo de rock argentino Sui Generis, el más importante a nivel local para esas fechas. Véase Delgado (2016, pp. 17-48).

\section{Bibliografía Musical}

Baez, J. (1974). Gracias a la vida [LP]. Hollywood, EU: A\&M Records.

Sosa, M. (1971). Homenaje a Violeta Parra [LP]. Buenos Aires, Argentina: Phillips Records.

Sosa, M. (1973). Traigo un pueblo en mi voz [LP]. Buenos Aires, Argentina: Phillips Records.

Sosa, M. (1974). Canción con todos (1974) completo full álbum [Video de youtube]. Recuperado de https://www.youtube.com/watch?v=NDNuho1-duM

Parra, V (1966). Gracias a la Vida. En Las últimas composiciones [LP]. Santiago de Chile, Chile: RCA Víctor.

\section{Bibliografía General}

Alabarces, P. (1993). Entre gatos y violadores El rock nacional en la cultura argentina. Buenos Aires, Argentina: Colihue.

Althusser, L. (1998). Ideología y aparatos ideológicos de Estado. Freud y Lacan. Buenos Aires, Argentina: Nueva Visión.

---. (1967). La revolución teórica de Marx, (Trad. M. Harnecker). Buenos Aires, Argentina: Siglo XXI. 
Benveniste, E. (1977). Problemas de Lingüística general II. Buenos Aires, Argentina: Siglo XXI.

Charaudeau, P. (2009). Reflexiones para el análisis del discurso populista. Discurso \& Sociedad, 3 (2), 253-279.

Delgado, J (2016). El show de los muertos: música y política en el grupo de rock argentino Sui Generis. A contra corriente, 13 (3), 17-48.

De Szyszlo, F. (1977). Ponencia. En D. Bayón (Ed.) El artista Latinoamericano y su identidad. Caracas, Venezuela: Monte Ávila.

Dylan, B. (2004). Crónicas. Volumen I (Trad. M. Izquierdo). Madrid, España: Titivillus.

Franco, M. (2012) Un enemigo para la nación. Orden interno, violencia y subversión, 19731976. Buenos Aires, Argentina: Fondo de cultura económica.

Foucault, M. (1991). Michel Foucault: beyond structuralism and hermeneutics. Chicago, EU: Chicago Press, Carpe Diem Ediciones.

Frith, S. (1998). Performing Rites. On the value of popular music. Cambridge, EU: Harvard University Press.

García, M., Greco M., Bravo, N. (2014). Testimonial del Nuevo Cancionero: las prácticas musicales como discurso social y el rol del intelectual comprometido en la década del sesenta. Resonancias, 34 (18), 89-110.

Ghio, E. (2008). Lingüística Sistémico Funcional, Aplicaciones a la lengua española. Santa Fe, Argentina: Ediciones Universidad Nacional del Litoral.

González, C. (2003). La música en la Grecia antigua. Acta poética, 1 (24).

Hartshorne and Weiss. (Eds.). (1931-1958). Collected Papers of Charles Sanders Peirce, vols.

1-6. Cambridge, EU: Harvard University Press, 1931-1958.

Hobsbawm, E. (1999). Historia del Siglo XX. Barcelona, España: Grijalbo Mondadori.

Karush, M. (2017). Musicians in transit. Argentina and the globalization of popular music. Durham, EU: Duke University Press.

Lopez, E. (1987). Seguridad nacional y sedición militar. Buenos Aires, Argentina: Legasa.

Maingueneau, D. (2008). Términos Clave del Análisis del Discurso. Buenos Aires, Argentina: Nueva Visión.

Paz, O. (1977). Palabras al simposio. En D. Bayón (Ed.). El artista Latinoamericano y su identidad. Caracas, Venezuela: Monte Ávila.

Pêcheux, M. (1978). Análisis automático del discurso: críticas y perspectivas nuevas. En Hacia el análisis automático del discurso (Trad. M. Alvar, Gredos). Madrid, España: Gredos.

Pierce, Ch. (1987). Collected papers. En A. Sercovich (Ed.) Obra Lógico Semiótica (Trad. R. Recalde). Madrid, España: Taurus. 
Pujol, S. (2007). Rebeldes y modernos. Una cultura de los jóvenes. En D. James (Coord.). Nueva historia argentina Vol. 9 (pp. 281-329). Buenos Aires, Argentina: Sudamericana. Rancière, J. (1974). La lección de Althusser. Paris, Francia: Gallimard.

Ripoll, O. (1974). El verso cambiado. Revista Pelo 55, 8-12.

Rodríguez, C. (1977). Ponencia. En D. Bayón (Ed.). El artista Latinoamericano y su identidad. Caracas, Venezuela: Monte Ávila.

Rolnik, S. (2006). Cartografia Sentimental. Transformações contemporáneas do desejo. Porto Alegre, Brasil: Sulina.

Rolnik, S. (2006). Geopolítica del Rufián (o del chuleo, o del cafishio). Ramona, revista de artes visuales, 67 (2), 8-20.

Rosenstone, R. (2016). The times they are A-Changing. The music of protest. The ANNALS of the American Academy of Political and Social Science, 382 (1), 31-144.

Svampa, M. (2007). El populismo imposible y sus actores. En D. James (Coord.), Nueva Historia Argentina Vol. 9 (pp. 381-436). Buenos Aires, Argentina: Sudamericana.

Traba, M. (2005). La resistencia. En F. Bazzano-Nelson (Comp.) Dos décadas vulnerables en las artes plásticas latinoamericanas, 1950-1970. Buenos Aires, Argentina: Siglo XXI.

Turfó, M. (2010). Incitar, capturar, censurar, gestionar. Cien años de politización de la música argentina. En M. Ugarte (Coord.), Sonidos, tensiones y genealogía de la música argentina: 1910-2010. Buenos Aires Argentina: CCC y Fondo Nacional de las Artes.

Ugarte, M. (2010). Cien años de música entre la Nación, la resistencia y los géneros populares. En M. Ugarte (Coord.), Sonidos, tensiones y genealogía de la música argentina: 19102010. Buenos Aires Argentina: CCC y Fondo Nacional de las Artes.

Vila, P. (comp.) (2014). Music and Youth Culture in Latin America. Identity Construction Processes from New York to Buenos Aires. New York, EU: Oxford University Press.

Verón, E (1984). Semiosis de lo ideológico y del poder. Espacios de crítica producción, pp. 43 51. Recuperado de eliseoveron.com/archivos/1984/08/23/semiosis-de-lo-ideologico-ydel-poder

(25 de mayo de 2017). Joan Baez: "Hay que dejar de añorar los 60. Diario Clarín. Recuperado de clarin.com/rn/escenarios/Joan-Baez-dejar-anorar-60_0_SkeX24ysvml.html 